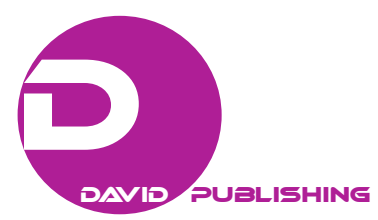

\title{
The Impact of Organizational Culture on Outsourcing Choice
}

\author{
Paolo Popoli \\ Parthenope University of Naples, Napoli, Italy
}

\begin{abstract}
Culture is a very wide concept if applied to entrepreneurial organizations, but it is also one of the most powerful drivers of entrepreneurial behaviour and choices. This paper is going to explore the impact of the organizational culture on outsourcing choices, providing conceptual insights in order to understand better the way the organizational culture can influence the evaluation of the factors conditioning the outsourcing decision. Even though the choice of outsourcing is mainly based on rational factors, the findings show that organizational culture could have a relevant influence on attitudes towards outsourcing, either in the choice planning and making stage or in the implementation one referring to the nature and to the structure of the client-vendor relationship. Methodologically, this paper is conceptual and based on reviewing existing research, and strives to contribute to existent literature putting together the theoretical concerns about organizational culture and strategic outsourcing.
\end{abstract}

Keywords: organizational culture, organizational change, outsourcing choices, cultural difference in outsourcing, critical factors in organizational change, uncertainty avoidance

\section{Introduction}

The outsourcing choices have been a sensational phenomenon within the entrepreneurial practice, concerning now almost every business activity, function, and process (Feeny, Lacity, \& Willcocks, 2012; Leavy, 2001; Marjit \& Mukherjee, 2008). More than the great diffusion from the quantitative point of view, the outsourcing phenomenon development concerned most of all the continuous widening of goals and contents non restricting to the outsourcing of business activities and functions characterized by a little management complexity and by a little strategic significance (commodities), but also concerned other activities, functions and even complete processes characterized by a strong impact on company competitiveness and on the value creation processes. Eventually there has been a proliferation of different kinds of outsourcing which came from the more traditional tactical outsourcing to the more complex strategic outsourcing, business process outsourcing and transformational outsourcing.

The phenomenon evolution can be seen from the point of view of its goals and in particular if once outsourcing was essentially aimed to achieve cost reduction, now goals linked to knowledge, expertise and technology held by third companies prevail (Maskell et al., 2007; McIvor, 2000); these goals are based on a high management and control ability of relational dynamics that companies have been developing through experiential learning (P. Popoli, \& A. Popoli, 2009). Approaching outsourcing strategically, firms have learned to discuss with the company outsourcing strategy perspective which constitutes the most innovating feature in

Paolo Popoli, associate professor, Parthenope University of Naples, Napoli, Italy.

Correspondence concerning this article should be addressed to Paolo Popoli, Via Generale Parisi 13, 80133 Naples, Italy. 
the business system organization in a hypercompetitive and globalized contest as the one we live in (Brown \& Wilson, 2005; Popoli, 2011).

The outsourcing choices are made through a complex choice process usually divided into the following stages:

- Evaluation and decision to outsource and what to outsource;

- Definition of objectives;

- Choice of provider;

- Negotiation of terms and conditions; service-level agreement, stipulation of contract;

- Managing relations;

- Monitoring and evaluation of results

For this essay's goal, it is important to underline how each stage is set using a range of criteria pre-arranged by every company aiming to give the process the higher level of "rationality". The thesis upheld by this essay is that the choice is not only made by rational elements, but also by organizational culture conditioning every stage of the process above described. The conditioning can emerge in two ways, implicitly and tacitly. In fact, organizational culture is partly implicit because it is included in the criteria and procedures used in the choice, and partly tacit because unconsciously characteristic of every single individual working in a company, both as top manager having the organizational responsibility of the choice and as middle and low manager who is the one concretely appointed to improve the choice of outsourcing made. This has happened since outsourcing has to be defined inside strategic and organizational change processes, so it cannot avoid cultural interferences and changes going with every company change. In the case of outsourcing, organizational culture has to be considered as a very outstanding and conditioning factor for the choice making and its implementation, as well as relationship management between client and vendor.

Having said that this paper aims to provide conceptual insights on this subject and to represent a useful reference to further studies and future research, it is organized as follow: after this introduction, the second section provides a conceptual background about the idea of organizational culture; the third section analyses the organizational culture as a conditioning factor towards organizational change, in particular how organizational culture can enable or retard the change; the fourth section deals with the central topic of this essay in order to discuss the way organizational culture interferes with outsourcing choices, providing a deeper conceptual understanding of its role; finally, in the conclusion, limitations of this study and future research are identified.

\section{Conceptual Background on Organizational Culture}

Organizational culture is one of the widest concepts which could be seen from various perspectives, and it has been conceptualized by very different subjects, such as sociology, psychology, anthropology and management. Among these, the management science perspective observes what organizational culture means in terms of organizational "dimension” and how it impacts behaviour and choices made by firms.

From this point of view, researchers have defined organizational culture according to values and beliefs, patterns, symbols, ritual, and myths, as a holistic construct guiding organization through its behaviour and choices (Schwartz \& Davis, 1981; Schein, 1992; Trice \& Beyer, 1984). So, organizational culture refers to shared values, beliefs, expectations and practice shaping and guiding individuals' attitudes and behaviour (Davis, 1984; Rousseau, 1990), and this is what differentiates an organization from the others. According to Shein (1985), one of the most famous researchers into this topic, organizational culture can be defined as "a 
pattern of shared basic assumptions that the group learned as it solved its problems of external adaptation and internal integration, that has worked well enough to be considered valid and therefore, to be taught to new members as the correct way to perceive, think and feel in relation to those problems” (p. 9). The author considers organizational culture as a construct where you can identify three domains (Figure 1): (a) artifacts, such as procedures, organizational structures, as well as visible behaviour, styles and even clothing; (b) espoused values, made by the complex of rules, values, beliefs, standards, and prohibitions; (c) basic underlying assumptions, which are the invisible essence of organizational culture, the ones determining the perceptions, the feelings, and all is beneath the individuals' behaviour. In this model, the three domains interact with each other and give the organizational culture a precise identity.

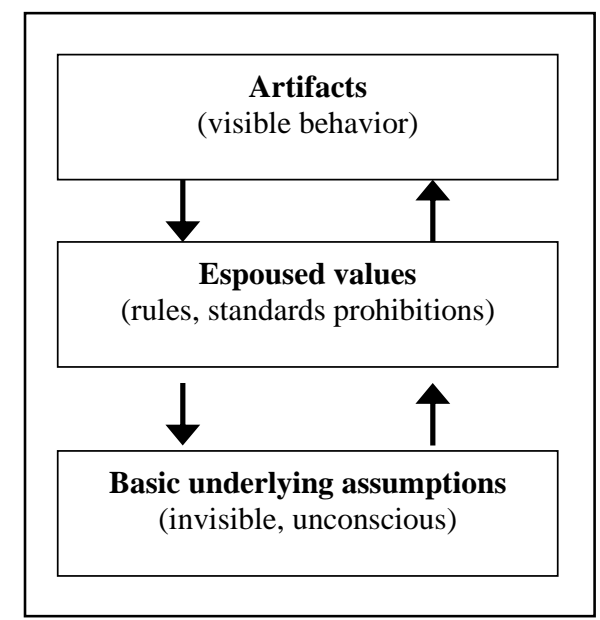

Figure 1. The “domains” of organizational culture by Shein (1992).

Another very famous conceptualization of organizational culture has been proposed by Hatch (1993), who highlights the processes that link assumptions, values, artifacts, and another element which is "symbols". The author assumes that the processes linking the four elements are manifestation, realization, interpretation, and symbolization, as shown in Figure 2.

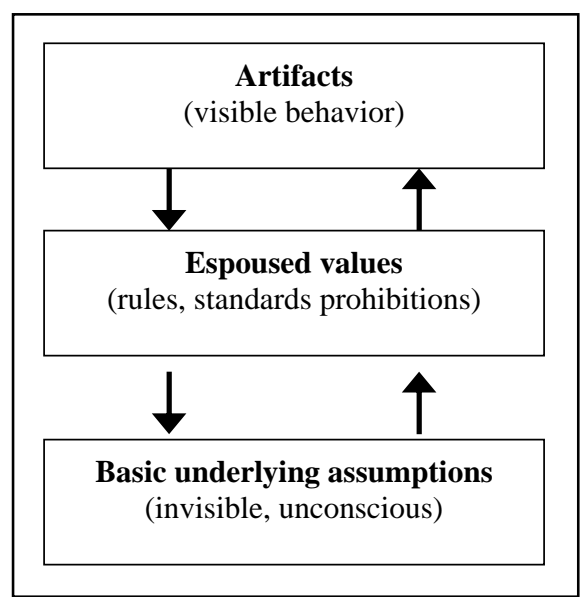

Figure 2. The “processes” of organizational culture by Hatch (1993).

Organizational culture is also a concept referring to formal and informal elements, and it is the result of a combination of them (Hofstetter \& Harpaz, 2015). Moreover, organizational culture is influenced not only by 
the internal environment but also, at the same time, by the external environment. From this point of view, organizational culture is influenced from the national or societal culture, as pointed out by Hofstede (1980, 2001) in his books and papers, and more recently by Sagiv and Schwarts (2007). As many others, the authors claim organizational culture as influenced by the norms, values, and regulations of societies, since members introduce into the organization their own cultural background formed within their specific societal context.

Another important point to underline is the internal and external dimension of the organizational culture concept. According to Tsui et al. (2007), organizational culture is a construct incorporating five cultural values: employee development, harmony, customer orientation, social responsibility and innovation. Employee development and harmony refer to the internal integration of organizational culture, while customer satisfaction, social responsibility and innovation refer to the external adaptation of the organizational culture. So, once again, the organizational culture concept is interpreted as a holistic construct able to identify an organization within both the internal context and the external context, in a specific way which differentiates it from other organizations.

In sum, according to Cartwright and Cooper (1993), culture is to an organization what personality is to an individual. As well as personality, organizational culture is unique to a particular organization, and concerns tradition, shared values and beliefs, shared expectations about organizational life, referring to the present as well as to the future. This is the reason why organizations show very often a relevant resistance towards organizational change, since organizational culture is the result of the successfully adapting to the internal and external environment (Gordon, 1991).

\section{Organizational Culture as Conditioning Factor Towards Organizational Change}

According to Schein (1985), organizational culture is a set of basic underlying assumptions and guiding principles affecting the way of doing business. In particular, organizational culture impacts on all organizational domains, strategy, structure, and operations, in a hierarchical order in which there is a learning process allowing the organization learn and adjust each element in function of the others.

The link between organizational culture and strategy and in particular between organizational culture and strategic change is important for this study to achieve its goal. Gordon (1991) assumes that organizational culture is a result of the successfully adaptation to the environment. In the current globalized scenario, the external environment changes very quickly and it is really difficult for organizations to follow this continuous and rapid technological, economic, societal, and political evolution. As a consequence, it is reasonable that organizations show some difficulties and inertial forces to change, because this adaptation process involves change in organizational culture, whose formation and consolidation is processes being slower than the environmental change. Moreover, the organizational change is unique in each situation, because of the nature of the organization, the business nature, the management style, the values, and the behaviour successfully experienced in the past.

Every organizational change involves technological, organizational and personal factors, as pointed out by Linstone and Mitroff (1994), and among these, people are undoubtedly the most difficult element to cope with. This is due to the fact that people are generally more comfortable with what they have learned or knew, while they show resistance towards the change and in particular towards uncertainty and what is unknown or risky. As a consequence, as Dunham (1984) affirms, the crucial factor for being any change effective is the way organization deals with the individuals' beliefs, values, assumptions, and attitudes. 
Similarly, Juechter et al. (1998) assume that most important leverage for significant and realistic change resides within the human sphere at the core of every business system.

People are generally worried about the substantive change in job, reduction in economic security, and lowering of status and psychological aspects as well. Elizur and Guttman (1976) suggested that there are three dimensions of individuals' reaction to organizational change: affective, cognitive, and instrumental. Affective reaction refers to the feeling of satisfaction or anxiety relating to the change; cognitive reaction refers to the opinions about knowledge required by the change, and its usefulness and necessity; instrumental reaction refers to the concrete actions required by the change in the professional sphere.

Based on these assumptions, organizational culture can enable or retard the change depending on whether organizational culture is favourable or unfavourable to such a process. Resuming the above mentioned concepts of internal integration and external adaptation, you can distinguish two different types of organizational culture, namely "integrative" culture and "hierarchical" culture.

Organizations with integrative culture show strongly and widely shared values facilitating both internal integration and external adaptation; in fact, this kind of organization emphasizes both the values of caring for employers, customers, and society, which help for the internal integrating process, and values for innovation and high performance, which help for the external adaptation process (O’Reilly et al., 1991). In fact, if an organization presents among its basic values the care for the employers, customers and society, in general it seems to be more flexible and ready to change, because in its strategy it is supported by employers returning this attention to the organization as a greater sense of belonging, of commitment, and a greater trend to higher levels of organizational performance. As pointed out by Schein (1992), organizations with integrative cultures show a high attention towards the five elements. Tsui et al. (2007) identify as part of the concept of organizational culture, namely employee development, harmony, customer orientation, social responsibility and innovation.

Differently, the organizations with hierarchical culture show lower attention towards the five elements of the organizational culture and do not found their aims pursuing and operating logics on shared values but on the formal rules and the coordination mechanisms based on hierarchy and strict supervision. In these situations, the employers seem to be less ready to innovation and change and, on the contrary, tend to find a greater sense of security in continuity; hardly they go over the obedience of what organization asks them for and they are less willing to assume the risks and the uncertainty deriving from the change. For these reasons organizations with hierarchical culture are less able to promote both internal integration and external adaptation (Naranjo-Valencia et al., 2011).

\section{The Impact of Organizational Culture on the "Degree of Openness" to Outsourcing}

"Degree of openness" to outsourcing means the propensity and attitude that a firm has towards opening up their business system to the participation of third parties, externalizing important activities, functions, and entrepreneurial processes highly significant from a strategic stand point.

The idea of studying the concept of degree of openness of firms to outsourcing roots in the acknowledgment that, despite the fact that firms often claim to be willing and capable of opening up to the surrounding environment and managing cooperative dynamics with other organizations, empirical observation has reported difficulties or resistance which condition the choice to entrust to outside providers certain entrepreneurial activities, processes, or functions; furthermore, these factors also affect the nature of the 
inter-organizational dynamic that develops between the client and vendor.

The firm's "degree of openness to outsourcing" is determined, first and foremost, by three rational factors: the need for change, the benefits, and the risks associated with the decision. In particular, the degree of openness of a firm to outsourcing engagements depends on:

- First of all, the ability to capture the need for change, and specifically the external and internal pressures that demand changes in the architecture of the firm's business system, requiring structural interventions on the chain of value;

- Secondly, the greater value that may be achieved through the outsourcing of activities, processes, or functions, specifically in reference to the exploitation of the supplier's innovative capacity, and to its potential contribution to the generation of sources of competitive advantage;

- Thirdly, from the risk attributed to outsourcing, it often ascribable to the subject's limited rationality more so than the objective uncertainty of specific events.

These three factors have different effects on the formulation of the final decision: specifically, the decision to outsource is, on the one hand, positively correlated to the need for change and the benefits of outsourcing, and, on the other hand, inversely correlated to the totality of economic, strategic, and organizational risks which may be associated with the choice to outsource.

Nevertheless, the decision to outsource does not only depend on the above mentioned rational factors, but also on cultural factors of which the firm may be more or less conscious.

First of all, as underlined in the previous pages, the cultural factors affecting the outsourcing choices come whether from the organizational culture or the societal or National culture. As said, even if organizational culture and societal culture are conceptually two different elements, there is a strong interdependence and mutual influence link between them.

Therefore, before considering the specific analysis of the impact of organizational culture produces on the outsourcing choices, it can be useful to make some concise comments about the impact the societal culture makes on the outsourcing choices and on the ways these are depicted by.

This preliminary analysis aims to underline the importance of a particular element which more than the other ones affects the outsourcing choices, that is the trust level people, directly, and organizations, indirectly, show when set about establishing a relationship with a possible interlocutor-partner (Van der Meer-Kooistra \& Vosselman, 2000; Wicks, Berman, \& Jones, 1999).

Focusing this analysis on the popular and widely known Hofstede's culture theory (1980, 2001), there are some studies which analysed the link between trust and each one of the Hofstede's cultural dimension, namely individualism, power distance, uncertainty avoidance, and masculinity. Excepting the last one, about the first three dimensions there are some researches confirming the existence of a link between each one of these and the trust level shown by people during a relation. So Realo, Allik, and Greenfield (2008), and Etzioni (1993) demonstrate that in countries where collectivism prevails over individualism there is a higher interpersonal trust level; Putnam (2000) shares the same view and makes the same remark through a different observation, that is people, even autonomous and self-interested, admit that the pursuit of individual benefits cannot occur beyond the pursuit of collectivistic goals. Concerning the power distance, Huff, Couper, and Jones (2002) uphold that the more people feel the power distance level living in a society characterized by a high hierarchic order, the less they have trust in other people. Finally, considering the uncertainty avoidance, Inglehart (1997) affirms that higher uncertainty avoidance impacts negatively on interpersonal trust, since people are more inclined to 
confine their trust to their family and to a limited number of people rather than placing it in strangers.

Secondly, referring to the organizational culture, it is necessary to consider that one of the most underestimated factors driving outsourcing decision-making is the phenomenon of firm's path dependency. As stated by Arthur (1989), it often happens that once a choice has been made on the basis of a series of coincidental economic events, it will be locked-in independently of the advantages that may be obtained through the adoption of alternative choices. In some cases, the phenomenon of path dependency constitutes a defence of the integrity of the structure and a safeguarding of conditions which have produced a positive performance; on the other hand, in some cases this might simply translate into a limit that the firm self-imposes during its evolution, and that will be an impediment to the growth and improvement of its performance. The phenomenon of path dependency may manifest in any type of strategic or operational decision, thus playing a role also in reference to outsourcing processes. As was shown by Mol and Kotabe (2011), some firms demonstrate an "outsourcing inertia" which consists in a reduced ability to respond to demands for change coming from the external environment.

Thirdly, organizational culture also means relational culture, which could be representing both an incentive and an impediment towards the decision to outsource. In this regard, it shall be highlighted how a low relational culture essentially represents a scarce propensity to cooperation, a certain degree of mistrust towards other economic actors, and, in some cases, an entrepreneurial, centralizing, and self-centred protagonism which becomes reflected in decision-making processes, often interfering with factors of economic rationality. In this regard, it is interesting to note Greaver's (1999) statement, that some motivations expressed by managers to argue in favour of the rejection of outsourcing opportunities are nothing but "excuses" that strive to hide the difficulties encountered in change, rather than representing genuine manifestations of reasonable caution: "it needs to be further studied"; "we are currently too busy to carry out these studies"; "it is a good idea, but not the right time"; "there are too many hidden costs in outsourcing".

Fourthly, it should be considered that the role of relational culture increases in significance as the outsourcing starts to assume the features of a medium- or long-term partnership, as opposed to a short-term commercial transaction. Indeed, in the former case the governance mechanism cannot limit itself to "contract governance", or in other words to the formal regulation of mutual rights and duties, as defined by a contract, but rather requires a "relational governance" approach based on (Yang, Wacker, \& Sheu, 2012) the activation of "social mechanisms" through which it would be possible to carry out an exchange of information, a flexible interaction, and a joint resolution of problems that may arise from time to time during the course of the partnership (Behrens, 2006; McIvor, 2005). Han, Lee, and Seo (2007) stated that "the interactions between the client and the vendor often go beyond rules, agreements and exceptions; they also depend on intangible factors that cannot be easily incorporated into a contract” (p. 31).

On the basis of these considerations, what needs to be highlighted is that the identification of need for change, the analysis of the benefits of outsourcing, and the assessment of the risks related to this choice are in reality activities which are carried out in a subjective manner; consequently, the results of these activities of analysis and assessment are never subjective; rather, they are "perceptions of need for change", "perceived benefits", and "perceived risks".

Consequently, a firm's degree of openness to outsourcing is highly conditioned by the cultural factors which influence the rational factors that drive the decision-making process outsource. 


\section{Conclusion}

This paper has investigated the impact organizational culture has on organization choices. To that end the remarks started, according to a deductive logic, from the analysis of the role played by organizational culture on change processes in general, to specify our observations on the main theme of work, that is related it to outsourcing choices. Through the different aspects of the organizational culture concept the study reached the identification of the differently identified dimensions which affect directly the choice of outsourcing. For this purpose, it has been shown that the organizational culture influences the evaluation of the three main factors considered as critical for the outsourcing choice by top manager, and in particular need for change, benefits, and risks.

The thesis put forward in this paper claims that the three factors are usually considered as "rational", actually do not. On the contrary, they are very conditioned by the organizational culture and hence the outsourcing choices derive from a complex process of analysis and evaluation, subjective and not objective, partly conscious and partly unconscious.

The aim was essentially to provide some conceptual insights which could be further enriched or better specified by future research. In particular, future research could pass the limits of this study through the closer examination of the dimensions of organizational culture which could impact on outsourcing choices; moreover they could enrich the content of organizational culture going beyond the identified elements; finally differentiating the analysis on the basis of the kind of outsourcing made, that is on the object and the aim of a specific activity functioned on outsourced process.

\section{References}

Arthur, W. B. (1989). Competing technologies, increasing returns and lock-in by historical events. The Economic Journal, 99, 116-131.

Behrens, S. (2006). Governance and information systems outsourcing: A contingency perspective. In F. Lehner, H. Nosekabel, and P. Kleinschmidt (Eds.), Multikonferenz Wirtschaftsinformatik (pp. 101-116).

Brown, D., \& Wilson, S. (2005). The black book of outsourcing. New Jersey: John Willey and Sons, Inc.

Cartwright, S., \& Cooper, C. L. (1993). The role of culture compatibility in successful organizational marriage. Academy of Management Executive, 7, 57-70.

Davis, S. (1984). Managing corporate culture. Balinger, Cambridge, MA.

Dunham, R. B. (1984). Organizational behavior: People and process in management. Homewood, IL: Richard D. Irwin.

Elizur, D., \& Guttman, L. (1976). The structure of attitudes toward work and technological change within an organization. Administrative Science Quarterly, 21, 611-623.

Etzioni, A. (1993). The spirit of community: The reinvention of American society. New York: Simon \& Schuster.

Feeny, D., Lacity, M., \& Willcocks, L. (2012). Taking the measure of outsourcing providers. MIT Sloan Management Review, 46(3).

Greaver, M. F. (1999). Strategic outsourcing: A structured approach to outsourcing decisions and initiatives. New York: Amacom.

Gordon, G. G. (1991). Industry determinants of organizational culture. Academy of Management Review, 16, 396-415.

Han, H. S., Lee, J. N., \& Seo, Y. W. (2007). Analyzing the impact of a firm's capability on outsourcing success: A process perspective. Information \& Management, 45, 31-42.

Hatch, M. J. (1993). The dynamics of organizational culture. Academy of Management Review, 18, 657-693.

Hofstede, G. (1980). Culture's consequences: International differences in work-related values. Beverly Hills: Sage.

Hofstede, G. (2001). Culture's consequences: Comparing values, behaviors, institutions and organizations across nations. London: Sage.

Hofstetter, H., \& Harpaz, I. (2015). Declared versus actual organizational culture as indicated by an organization's performance appraisal. The International Journal of Human Resource Management, 26(4), 445-466. 
Huff, C. L., Couper, J., \& Jones, W. (2002). The development and consequences of trust in student project groups. Journal of Marketing Education, 24(1), 24-34.

Inglehart, R. (1997). Modernization and postmodernization: Cultural, economic, and political change in 43 societies. Princeton University Press.

Juechter, W. M., Caroline, F., \& Alford, R. J. (1998). Five conditions for high performance cultures. Training and Development, 52(5), 63-67.

Leavy, B. (2001). Supply strategy—What to outsource and where. Irish Marketing Review, 14(2), 46.

Linstone, H. A., \& Mitroff, I. I. (1994). The challenges of the 21st century. New York, NY: State University of New York Press.

Marjit, S., \& Mukherjee, A. (2008). International outsourcing and R\&D: Long-run implications for consumers. Review of International Economics, 16, 1010-1022.

Maskell, P., Pedersen, T., Petersen, B., \& Dick-Nielsen, J. (2007). Learning paths to offshore outsourcing: From cost reduction to knowledge seeking. Industry and Innovation, 14(3), 239-257.

McIvor, R. T. (2005). The outsourcing process: Strategies for evaluation and management. Cambridge, Cambridge University Press.

McIvor, R. (2000). A practical framework for understanding the outsourcing process. Supply Chain Management: An International Journal, 5(1), 22-36.

Mol, M. J., \& Kotabe, M. (2011). Overcoming inertia: Drivers of the outsourcing process. Long Range Planning, 44(3), 160-178.

Naranjo-Valencia, J. C., Jiménez-Jiménez, D., \& Sanz-Valle, R. (2011). Innovation or imitation? The role of organizational culture. Management Decision, 49(1), 55-72.

O’Reilly, C. A., Chatman, J. A., \& Caldwell, D. F. (1991). People and organizational culture: A profile comparison approach to assessing person-organization fit. Academy of Management Journal, 3, 487-516.

Popoli, P., \& Popoli, A. (2009). Old and new paradigms for IT services offshoring. International Journal of Information Systems in the Service Sector, 1(3), 47-64.

Popoli, P. (2011). IT services offshoring: opportunities and critical factors from a strategic perspective. Information Systems and New Applications in the Service Sector: Models and Methods, 1(3), 240-258.

Putnam, R. D. (2000). Bowling alone: The collapse and revival of American community. New York: Simon and Schuster.

Realo, A., Allik, J., \& Greenfield, B. (2008). Radius of trust: Social capital in relation to familism and institutional collectivism. Journal of Cross-cultural Psychology, 39(4), 447-462.

Rousseau, D. M. (1990). Quantitative assessment of organizational culture: The case for multiple measures. In B. Schneider (Ed.), Organizational climate and culture. London: Jossey-Bass.

Sagiv, L., \& Schwartz, S. H. (2007). Cultural values in organisations: Insights for Europe. European Journal of International Management, 1, 176-190.

Schein, E. H. (1985). Organizational culture and leadership. San Francisco, CA: Jossey-Bass.

Schein, E. H. (1992). Organizational Culture and Leadership (2nd ed). San Francisco, CA: Jossey-Bass.

Schwartz, H., \& Davis, S. M. (1981). Matching corporate culture and business strategy. Organizational Dynamics, 10(1), $30-38$.

Trice, H. M., \& Beyer, J. M. (1984). Studying organizational cultures through rites and ceremonials. Academy of Management Review, 9, 653-669.

Tsui, A. S., Nifadkar, S. S., \& Ou, A. Y. (2007). Cross-national, crosscultural organizational behavior research: Advances, gaps, and recommendations. Journal of Management, 33, 426-478.

Van der Meer-Kooistra, J., \& Vosselman, E. G. J. (2000). Management control of interfirm transactional relationships: The case of industrial renovation and maintenance. Accounting, Organizations and Society, 25(1), 57-77.

Wicks, A. C., Berman, S. L., \& Jones, T. M. (1999). The structure of optimal trust: Moral and strategic implications. The Academy of Management Review, 24(1), 99-116.

Yang, C., Wacker, J. G., \& Sheu, C. (2012). What makes outsourcing effective-A transaction cost economics analysis. Retrieved from http://krex.ksu.edu 